\title{
An evaluation of potential reference genes for stability of expression in two salmonid cell lines after infection with either Piscirickettsia salmonis or IPNV
}

Andrea A Peña ${ }^{1 *}$, Niels C Bols², Sergio H Marshall ${ }^{1}$

\begin{abstract}
Background: Due to the limited number of species specific antibodies against fish proteins, differential gene expression analyses are vital for the study of host immune responses. Quantitative real-time reverse transcription PCR (qRT-PCR) is one of the most powerful tools for this purpose. Nevertheless, the accuracy of the method will depend on the careful selection of genes whose expression are stable and can be used as internal controls for a particular experimental setting.
\end{abstract}

Findings: The expression stability of five commonly used housekeeping genes [beta-actin (ACTB), elongation factor 1-alpha (EF1A), ubiquitin (UBQ), glyceraldehyd-3-phosphate dehydrogenase (GAPDH) and tubulin alpha (TUBA)] were monitored in salmonid cell lines CHSE-214 and RTS11 after infection with two of the most fastidious fish pathogens, the facultative bacterium Piscirickettsia salmonis and the aquabirnavirus IPNV (Infectious Pancreatic Necrosis Virus). After geNorm analysis, UBQ and EFIA appeared as the most stable, although EFIA was slightly upregulated at late stages of $P$. salmonis infection in RTS11. ACTB instead, showed a good performance in each case, being always considered within the three most stable genes of the panel. In contrast, infection-dependent differential regulation of GAPDH and TUBA was also demonstrated.

Conclusion: Based on the data presented here with the cell culture models CHSE-214 and RTS11, we suggest the initial choice of $U B Q, A C T B$ and EF1A as reference genes in QRT-PCR assays for studying the effect of $P$. salmonis and IPNV on the host immune response.

\section{Background}

To date, cDNA microarray and quantitative real-time reverse transcription PCR (qRT-PCR) have become the most important and reliable tools to study differential gene expression in fish, where species-specific antibodies are scarce. Although qRT-PCR combines advantages of specificity, sensitivity, speed, throughput and reproducibility over conventional methods an accurate normalization of data is fully required [1]. Errors in the quantification of mRNA transcripts arise from any variation in the amount of starting material between samples. A common strategy to overcome this problem is to

\footnotetext{
*Correspondence: andrea.pena@ucv.cl

'Laboratorio de Genética e Inmunología Molecular, Instituto de Biología,

Pontificia Universidad Católica de Valparaíso, Av. Brasil 2950, Valparaíso, Chile
}

simultaneously amplify a non-regulated housekeeping gene with those targeted to allow quantitative normalization of the experimental cDNA inputs. However, it has also been demonstrated that expression levels of these genes may vary considerably depending on cell types, tissues, experimental treatments and even under different diseases [2]. Moreover, the use of a single reference gene for normalization is nowadays discouraged by an increasing number of authors [3-5]. Consequently, it is highly necessary to validate their constitutive expression for a particular experimental setting and therefore a crucial component when assessing a new model [6].

The present study aims to validate the usefulness of five potential housekeeping genes for normalization of a number of salmonid relevant immune genes. We are 
currently developing SYBR Green based real-time assays for studying the host immune response influenced by the infection with the facultative bacterium Piscirickettsia salmonis and with the IPNV, respectively. The in vitro models CHSE-214 (an epithelial-like embryo cell line derived from Chinook salmon, Oncorhynchus tshawitscha) and RTS11 (monocyte/macrophage-like cell line derived from rainbow trout, Oncorhynchus mykiss) have been of great help for this purpose because they have been shown to be susceptible to a wide range of viral infections $[7,8]$ and to $P$. salmonis $[9,10]$. The potential reference genes we have examined are betaactin $(A C T B)$, elongation factor 1-alpha $(E F 1 A)$ and glyceraldehyd-3-phosphate dehydrogenase (GAPDH), which have been previously validated in several studies on diverse fish species including salmonids [11-13], and ubiquitin $(U B Q)$ and tubulin alpha $(T U B A)$, which have been reported for fish species like the three-spine-stickelback (Gasterosteus aculeatus [14]) and zebrafish (Danio rerio [15]), but not in salmonids. The five housekeeping genes were selected based on their previous use as internal controls for gene expression studies, the availability of housekeeping gene sequences for salmonids and related teleost species, and because they have roles in different cellular functions (Table 1), thus reducing the likelihood that they exhibited regulated covariation.

\section{Methods}

CHSE-214 was obtained from the American Type Culture Collection (ATCC CRL-1681), whereas RTS11 was developed by the middle author [16] (University of Waterloo, Canada). The routine growth of these cell lines has been described previously $[17,18]$. Briefly, CHSE-214 cultures were maintained at $17^{\circ} \mathrm{C}$ in MEM (Gibco) supplemented with $10 \mathrm{mM} \mathrm{NaHCO} 3,15 \mathrm{mM}$ HEPES and 5\% FBS (Gibco). RTS11 cultures were maintained at $20^{\circ} \mathrm{C}$ in Leibovitz's L-15 medium (Gibco) supplemented with $5 \%$ FBS. The cultures were free of mycoplasma, as determined by qualitative PCR.

Piscirickettsia salmonis type strain LF89 ATCC VR 1361 was grown in the cell line CHSE-214 as described previously [19]. Bacteria obtained from the culture supernatant of 15 days post-infection CHSE-214 cells were used to inoculate CHSE-214 and RTS11 cultures in $25 \mathrm{~cm}^{2}$ plastic tissue culture flasks (Orange) at a concentration of $4.0 \times 10^{5}$ cells $/ \mathrm{ml}$. Prior to inoculation, 1 $\mathrm{ml}$ aliquots from infected CHSE-214 culture were centrifuged for $10 \mathrm{~min}$ at $900 \times \mathrm{g}$ at $4^{\circ} \mathrm{C}$ to remove debris. The supernatants were transferred to fresh tubes and centrifuged for $30 \mathrm{~min}$ at maximal speed at $4^{\circ} \mathrm{C}$ to concentrate the bacteria. After the supernatants had been discarded, bacteria pellets were resuspended in the medium appropriate for each cell line. The titre of $P$. salmonis used in inoculums was $1 \times 10^{6.8} \mathrm{ml}^{-1}$. This titre was determined on CHSE-214 cells and calculated by the method of Reed and Muench [20]. For expression studies, cells were harvested at 2, 5 and 9 days postinfection.

Experiments with IPNV were performed using the Chilean strain VR299. The virus was propagated by inoculating CHSE-214 cell monolayers at a multiplicity of infection (MOI) of 0.1 to $1 \mathrm{PFU} /$ cell in MEM supplemented with $2 \%$ FBS and antibiotics. Infected cultures were incubated at $17^{\circ} \mathrm{C}$ and monitored until CPE was evident and the clarified supernatants were divided into aliquots that were stored at $-20^{\circ} \mathrm{C}$. Aliquots were titrated in a plaque formation assay as described previously [21]. For expression studies, both CHSE-214 and RTS11 cultures were inoculated at a MOI of $1 \times$, and cells were harvested at $6 \mathrm{~h}, 24 \mathrm{~h}$ and $48 \mathrm{~h}$ post-infection.

All experiments were carried out using three biological replicates, i.e. three independent tissue culture bottles for each time point and assayed independently. Controls were done alike. Times for harvesting P. salmonis- and IPNV- infected cultures were chosen as CPE advanced, but making sure that no significant cell death and lysis were taking place.

Total RNA extraction from cell cultures was carried out using Trizol $^{\circ}$ (Invitrogen) according to the manufacturer instructions. A NanoDrop ND 1000 spectrophotometer was employed to analyze RNA concentration and purity. All samples were DNase treated (RQ1 RNase-free DNase, Promega) to remove any contaminating DNA. For PCR amplification, first strand cDNA was synthesized from $1 \mu \mathrm{g}$ total RNA using oligo(dT) primer and the AffinityScript ${ }^{\mathrm{m}}$ QPCR cDNA Synthesis Kit (Stratagene).

Table 1 Name and function of candidate reference genes

\begin{tabular}{|c|c|c|c|}
\hline Symbol & Gene name & Function & $\begin{array}{l}\text { GenBank accession no. } \\
\text { (Oncorhynchus mykiss) }\end{array}$ \\
\hline$A C T B$ & Beta actin & Cytoskeletal structural protein & emb|AJ438158.1|OMY438158 \\
\hline EF1A & Elongation factor 1 alpha & Protein biosynthesis & gb|AF498320.1| \\
\hline GAPDH & Glyceraldehyd-3-phosphate-dehydrogenase & Glycolytic enzyme & gb|AF027130.1|AF027130 \\
\hline$U B Q$ & Ubiquitin & Protein degradation & dbj|AB036060.1| \\
\hline TUBA & Tubulin alpha & Structural protein & NM_001124691.1 \\
\hline
\end{tabular}


CHSE-214 and RTS11 cultures were monitored for infection by phase contrast microscopy (Olympus IMT2 microscope). P. salmonis PCR confirmation was carried out by using the primer pair RTS1/RTS4 against the ITS region of the bacterial 16S rRNA operon as described previously [22]. IPNV infections were confirmed by using 1 step RT-PCR procedure (Brilliant QRT-PCR Master Mix Kit 1-Step, Stratagene) with primer set VP2SNP-F/VP2SNP-R (Santi, unpublished) against to the $V P 2$ fragment sequence. Reverse transcription was performed by incubating at $50^{\circ} \mathrm{C}$ for 55 min followed by PCR amplification $\left(95^{\circ} \mathrm{C}\right.$ for $10 \mathrm{~min}, 35$ cycles of $30 \mathrm{~s}$ at $95^{\circ} \mathrm{C}, 30 \mathrm{~s}$ at $55^{\circ} \mathrm{C}$ and $30 \mathrm{~s}$ at $72^{\circ} \mathrm{C}$, and $72^{\circ} \mathrm{C}$ for $10 \mathrm{~min}$ ). Mycoplasma contamination was absent as tested by amplifying with the primer set MyF1/MyR1 (PCR Mycoplasma Detection Set - TaKaRa Biomedicals Takara Shuzo).

Five reference genes $(A C T B, U B Q, E F 1 A, G A P D H$ and $T U B A$ ), belonging to different functional classes, were selected to reduce the chance of their co-regulation (Table 1). All primers were designed on conserved regions so that they could amplify each gene in both species under study: O. mykiss and O. tschawitcha. Primers were evaluated with the OligoCalc application [23] to check annealing temperatures and self- complementarity. The specificity of the primers was tested using BLAST analysis against the nr NCBI database. Primer specifications are summarised on Additional file 1 . The desired amplicon length (182 - 204 base pairs) was chosen to be similar among all genes to avoid significant differences in PCR efficiencies due to amplicon length. PCR products were cloned into TOPO vector (pCR 2.1, Invitrogen) and submitted to sequencing for verification. Partial O. tschawitcha sequences were deposited into GenBank accession numbers: FJ890356 (EF1A), FJ890357 (ACTB), FJ890359 (UBQ) and FJ890358 (TUBA).

qRT-PCR was carried out using a MJ Research realtime cycler. Each reaction for amplification of housekeeping candidates contained: $10 \mu \mathrm{l}$ of the Brilliant II SYBR Green qPCR Master Mix (Stratagene), $100 \mathrm{nM}$ of forward and reverse primers and $2 \mu \mathrm{l}$ of 10 -fold diluted cDNA, to a final volume of $20 \mu \mathrm{l}$. PCR was achieved with 10 min activation and denaturation step at $95^{\circ} \mathrm{C}$, followed by 40 cycles of $30 \mathrm{~s}$ at $95^{\circ} \mathrm{C}, 30 \mathrm{~s}$ at the specific annealing temperature (see Additional file 1), $30 \mathrm{~s}$ at $72^{\circ} \mathrm{C}$ and $2 \mathrm{~s}$ at $74^{\circ} \mathrm{C}$ for fluorescence measurement. Following the final cycle, melting curve analysis were performed to examine the specificity in each reaction tube (absence of primer dimers and other

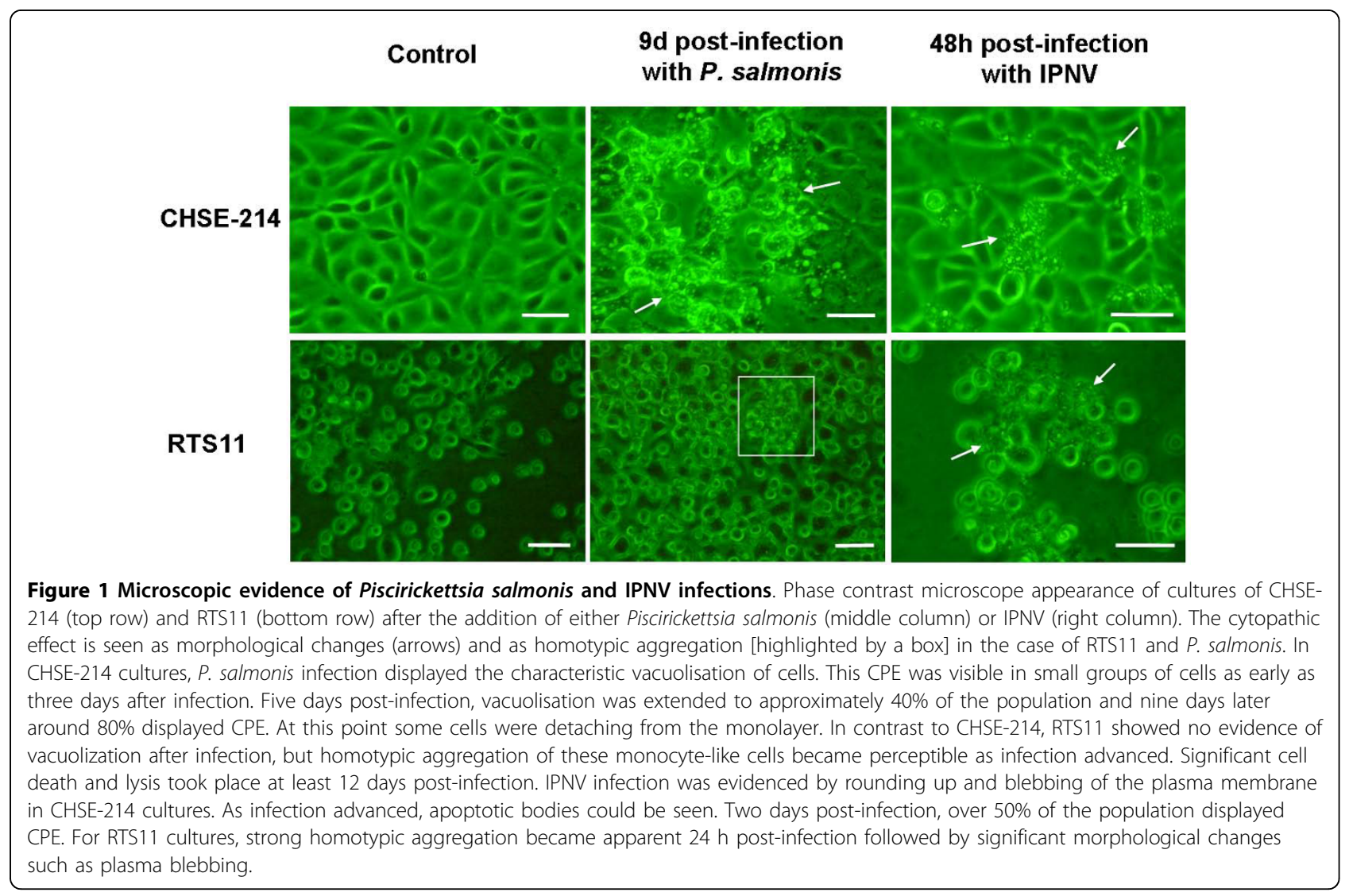


non-specific products) by heating the samples from 60 to $90^{\circ} \mathrm{C}$ in $0.2^{\circ} \mathrm{C}$ increments with a dwell time at each temperature of $5 \mathrm{~s}$ while continuously monitoring the fluorescence.

PCR efficiencies were calculated for each tissue culture cell line using a relative standard curve derived from a pooled cDNA mixture (a ten-fold dilution series with five measuring points). The pooled cDNA was obtained from control and infected samples from both CHSE-214 and RTS11 cell cultures, respectively, using the same RNA isolation and cDNA synthesis protocols as described above. The real-time PCR efficiencies were calculated from the slope according to the established equation $\mathrm{E}=10^{(-1 / \text { slope })}$ [4].

Real-time PCR were assayed on every biological replicate and each sample was run in duplicate. Each PCR reaction included reverse transcriptase negative controls for testing genomic DNA contamination and a non template negative control to check for primer dimer. To minimize experimental variation, each gene was quantified on the same batch of cDNA and the same gene was tested on the different samples in the same PCR run.

The threshold cycle $(\mathrm{Ct})$ values of the Opticon Monitor 2 software version 2.03 were transformed to relative quantities for analysis with the geNorm 3.5 software as described by Vandesompele et al. [3]. For the conversion of the Ct values to relative quantities [24], reaction efficiencies were used. Relative gene expression for $G A P D H, T U B A$ and $E F 1 A$ were calculated using the geometric mean of the three most stable genes of each assay as normalization factors and the $2 \mathrm{~d}$ (in P. salmonis assays) and the $6 \mathrm{~h}$ (in IPNV assays) controls as calibrators, respectively.

A Mann-Whitney test was used to determine significant differences in gene expression between groups and the calibrator samples. Significance was set at $\mathrm{P}<0.05$. These last statistical analyses were done using the SPSS 13.0 statistic package.

\section{Results and Discussion}

Intracellular pathogens such as bacteria and viruses modulate key cellular processes which may involve changes in reference gene expression [25,26]. Each pathogen manipulates several cellular transcription pathways in different degrees also according to the affected cell type [25,26]. Efficient infections with P. salmonis and IPNV have been evidenced by increasing cytopathic effect, as well as by accumulation of bacterial DNA and viral RNA over time in both CHSE-214 and RTS11 cell cultures (Figures 1 and 2). To rule out persistency, we made sure CPE was detectable resulting in productive infection (Figure 1). As well, no primer specific
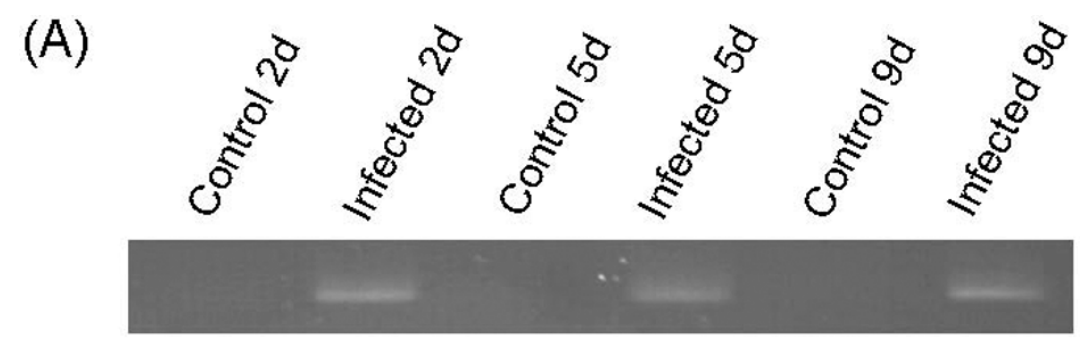

\section{CHSE-214}

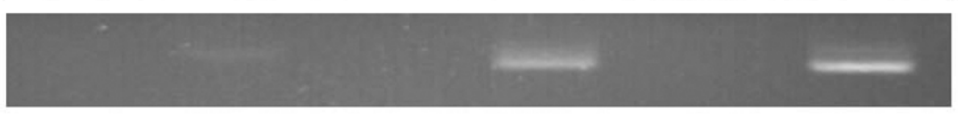

\section{RTS11}

\section{(B)}
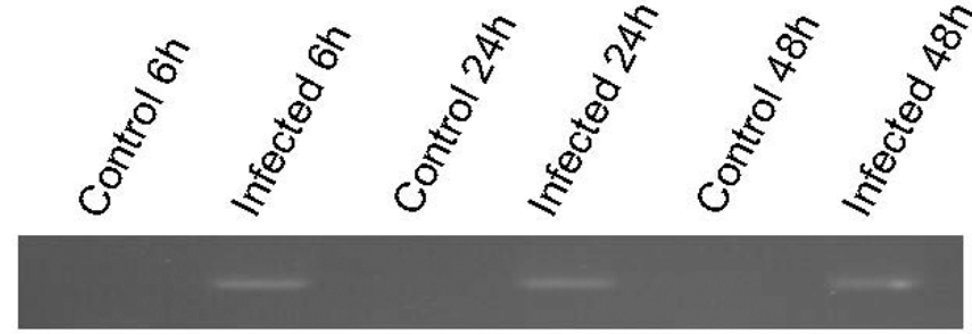

\section{CHSE-214}

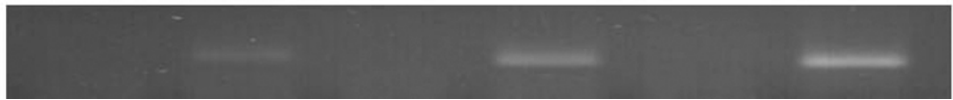

\section{RTS11}

Figure 2 Evidence of infection by PCR. PCR confirmation that cultures of CHSE-214 and RTS11 had been infected with either P. salmonis (A) or IPNV (B). P. salmonis was revealed by primer specific amplification of the ITS region of the bacteria 165 operon (A) and IPNV by primer specific amplification of the VP2 fragment (B). These results rule out persistency of infection in control samples, as they showed no primer specific amplification. 
amplification of the ITS region of the bacteria $16 \mathrm{~S}$ operon and the VP2 fragment of IPNV were evidenced in control samples (Figure 2). Despite progressive pathogen replication and accumulation in cultures, the expression of some reference genes remained constant, while others varied.

Prior validation of the selected reference gene candidates $(A C T B, E F 1 A, G A P D H, U B Q$ and TUBA), general expression levels based on mean qPCR threshold cycle (Ct) values in control CHSE-214 and RTS11 cells were determined, since extremely high or low expression levels might preclude their usefulness as internal controls (Figure 3). Ct values from 16.17 and 24.99 indicated expression levels in an appropriate range.

For each assay, a standard curve for RTS11 and for CHSE-214 samples was generated by using 10 -fold serial dilutions of pooled cDNA, generated from a mix of infected and control samples. Linear correlation coefficient $\left(R^{2}\right)$ varying from 0.9910 to 0.9998 and efficiencies between $87 \%$ and $96 \%$ showed that these assays were suitable for quantitative purposes (see Additional file 1).

The stability of gene expression over different samples can be achieved by evaluating qRT-PCR data with statistical algorithms. The geNorm software was chosen, since several studies have not found large differences between this tool and the NormFinder and the Bestkeeper $[14,26,27]$. GeNorm permitted to determine the internal control gene-stability measure $M$, which was calculated from the average pairwise variation of a particular gene with all other control genes. Genes with the lowest $M$ values have the most stable expression. Assuming that the control genes are not co-regulated, stepwise exclusion of the gene with the highest $M$ value results in a combination of two constitutively expressed housekeeping genes that have the most stable expression in the tested samples [3]. The ranking of the 5 candidate reference genes according to their $M$ value was very similar in all assays (Figure 4a).

In order to determine the optimal number of reference genes required for accurate normalisation, the pairwise variations $V_{n / n+1}$ between each combination of sequential normalisation factors $\mathrm{NF}_{\mathrm{n}}$ containing an increasing number of genes were calculated (Figure $4 \mathrm{~b}$ ). If the addition of a gene produced large differences between consecutives $V_{n / n+1}$, then the added gene should be preferably included for calculation of $\mathrm{NF}_{\mathrm{n}}$ [3]. Following this criteria, only the IPNV infection assay on RTS11 cell cultures might consider the inclusion of a

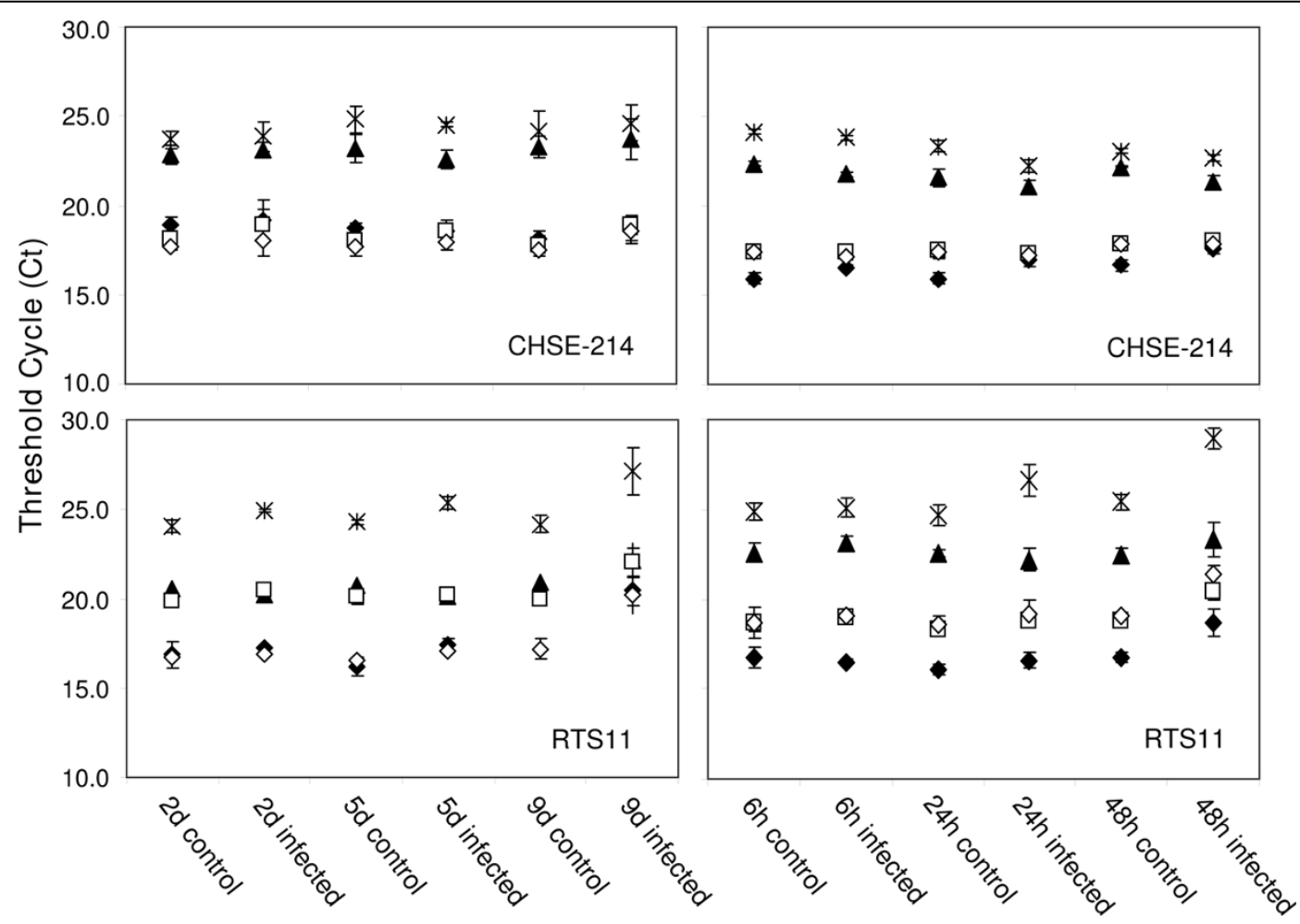

Figure 3 Transcriptional levels of candidate housekeeping genes measured by QPCR. Transcriptional levels (Ct values) of potential reference genes $\bullet A C T B, \square E F 1 A, \triangle G 3 P D H, \circ U B Q, * T U B A$ ) in cultures of either CHSE-214 (top panels) or RTS11 (bottom panels) at times after the addition of either $P$. salmonis (left panels) or IPNV (right panels). Each mark shows the mean Ct value (average of three biological replicates) included standard deviations. 


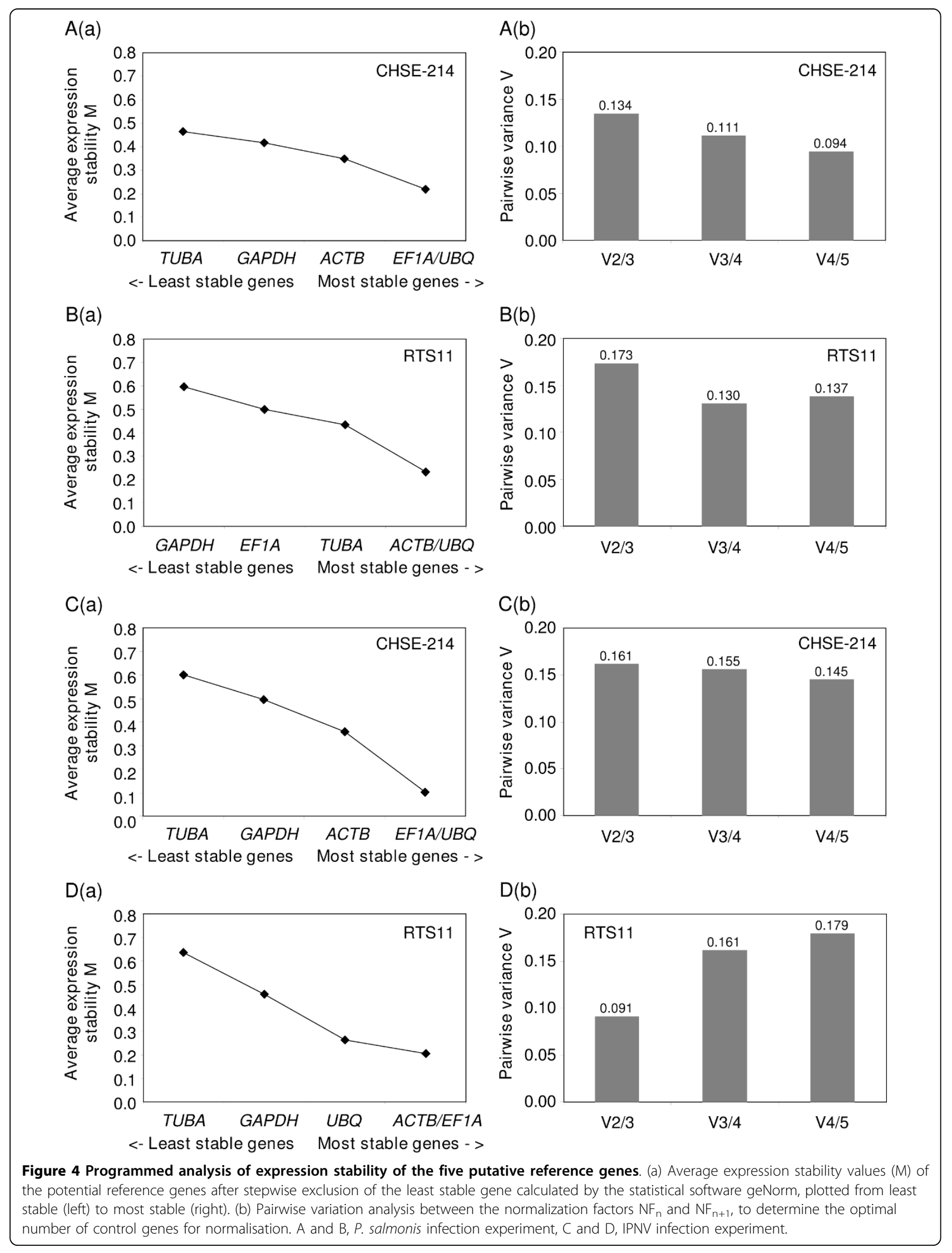


Table 2 Results of geNorm analyses

\begin{tabular}{llllll}
\hline & GAPDH & ACTB & EF1A & UBQ & TUBA \\
\hline CHSE-214-Ps & 0.418 & 0.350 & 0.217 & 0.217 & 0.465 \\
RTS11-Ps & 0.596 & 0.232 & 0.500 & 0.232 & 0.432 \\
CHSE214-IPNV & 0.496 & 0.358 & 0.101 & 0.101 & 0.599 \\
RTS11-IPNV & 0.457 & 0.205 & 0.205 & 0.263 & 0.636 \\
\hline Sum $_{\mathbf{p}}$ & 1.967 & 1.145 & 1.023 & 0.813 & 2.132 \\
\hline
\end{tabular}

The standard deviations of reference gene expression as determined by geNorm are shown.

(Sump: sum of pathogen infection geNorm values)

$4^{\text {th }}$ gene. For all other experimental settings, the optimal reference genes should be three.

$U B Q$ and $E F 1 A$ were the best ranked reference gene candidates, as they had the lowest $\operatorname{sum}_{\mathrm{p}}$ values $(0.813$ and 1.023, respectively) which represents the standard deviation (SD) of reference gene expression over all infections investigated (Table 2). EF1A has been demonstrated to be a good housekeeping gene for the analysis of infection challenges, although a slight upregulation in RTS11 cells after 9 days $P$. salmonis infection (Figure 5A). In contrast to the reports of modulated expression by viral infections of human cell lines [26] and in infection of Atlantic salmon with ISAV [11], ACTB showed in general a good performance during $P$. salmonis and IPNV infection, being considered in all cases as one of the three most stable genes (Figure 4a). As well, its reliability has been confirmed in LPS stimulated cells and tissues of fish [12] and birds [27].

In order to show how transcription profile of the least stable genes can be affected during each experimental setting, their relative transcription levels were determined using the normalization factor calculated from the geometric mean of the three most stable housekeeping genes (Figure 5). In agreement with several other studies on teleosts, GAPDH was one of the least stable genes in our panel $[13,15,28]$. In mammals GAPDH was shown to be influenced by a large number of

\section{(A)}

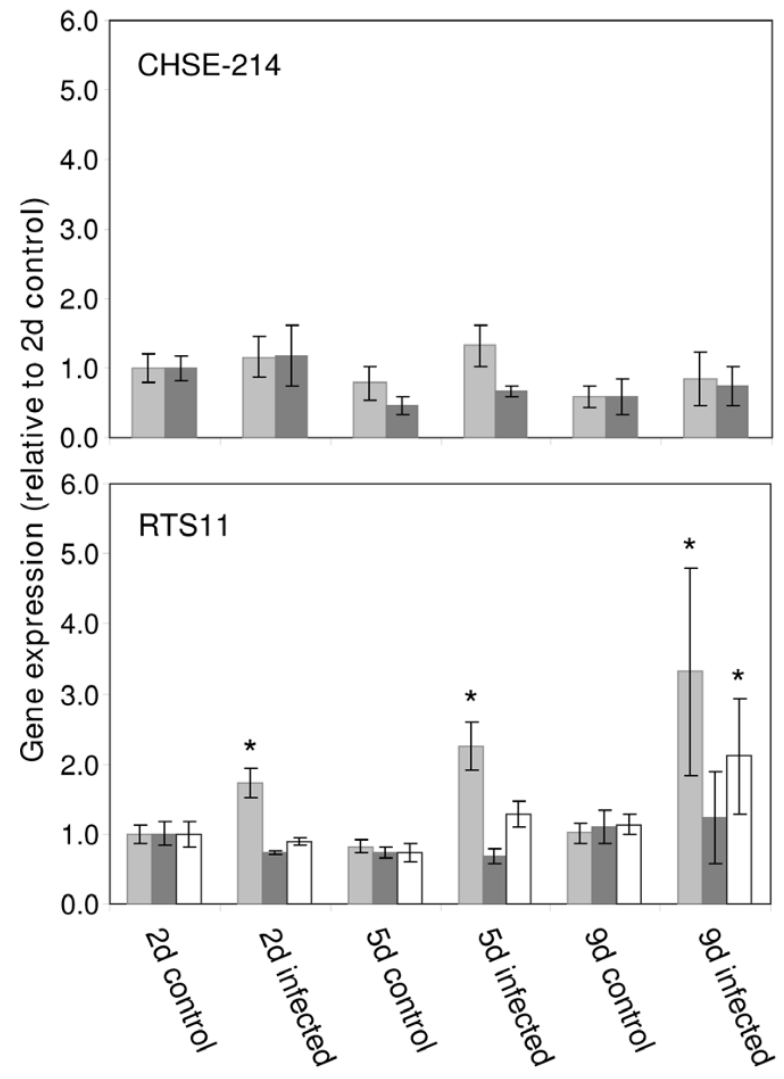

(B)

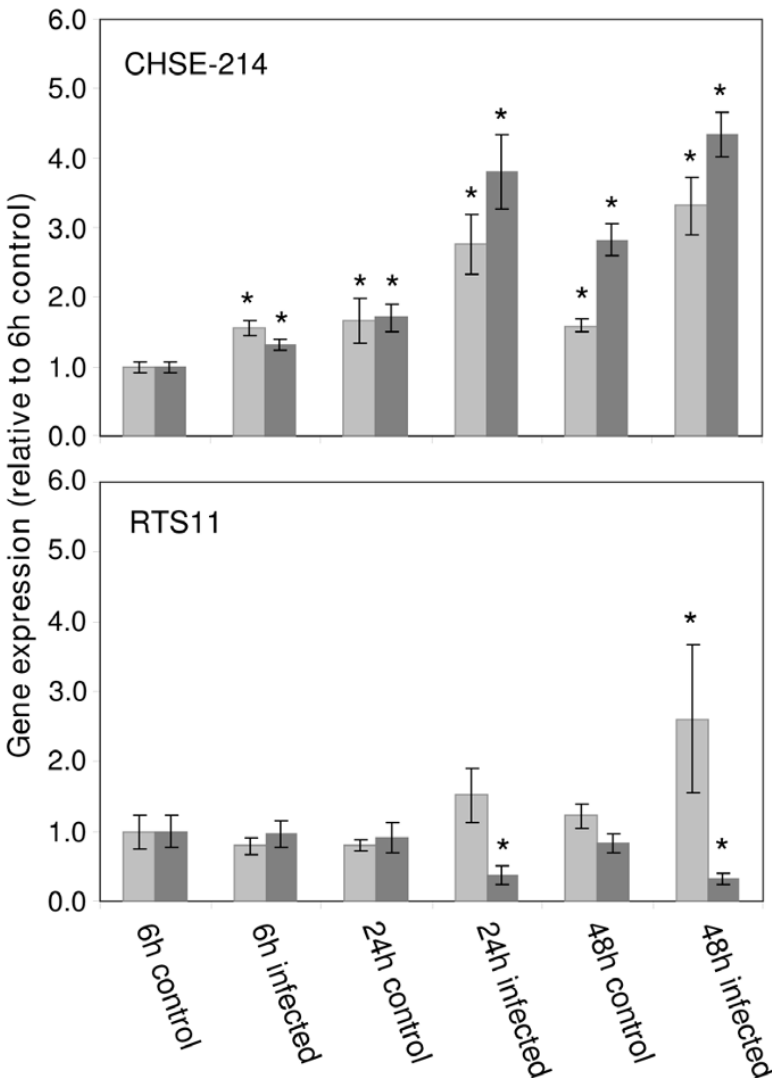

Figure 5 Normalized GAPDH, TUBA and EF1A gene expression. Relative mRNA levels for GAPDH (grey bars), TUBA (dark grey bars) and EF1A (white bars) at times after the addition of either P. salmonis (A) or IPNV (B). Gene expression was normalized by the geometric mean of the three most stable housekeeping genes determined by geNorm in each assay. The $2 \mathrm{~d}$ and the $6 \mathrm{~h}$ controls were used as calibrators (value $=1$ ) in the (A) P. salmonis and in the (B) IPNV assays, respectively. Bars represent the mean values ( \pm SE) for samples from three biological replicates. The asterisk $\left(^{*}\right)$ denotes significant differences from calibrators $(P<0.05$; Mann-Whitney test). 
physiological states and to play a role in a broad range of cellular mechanisms [29]. GAPDH expression was increasingly upregulated in RTS11 cells infected with $P$. salmonis and was slightly upregulated over $48 \mathrm{~h}$ in both control and IPNV-treated CHSE-214 cultures. This regulation on non-infected cells was not perceptible in the long-term experiment with $P$. salmonis or in the assays with RTS11. Schmitten and Zakrajsek [30] demonstrated that the addition of serum to serum-starved human fibroblast cultures increased the mRNA amount for GAPDH. Although in our experiments, cells were maintained in a low serum concentration $(5 \%$ fetal bovine serum), the addition of fresh media prior to infection could stimulate slightly the expression of GAPDH in the first few hours. Therefore, an important point to consider during the selection of a reference gene is whether expression could be eventually regulated by other factors than the challenge self. This differential regulation in the reference gene could lead to over- or sub-estimations of target gene expression. As well, TUBA showed increased expression over $48 \mathrm{~h}$ in both control and IPNV-infected CHSE-214 cultures, while in infected RTS11 cultures, TUBA was downregulated. Then, TUBA gene expression was influenced by IPNV infection but the direction of the influence depended on the cell type.

From our experiments using CHSE-214 and RTS11 as in vitro infection models for the study of immune host responses to the facultative bacteria $P$. salmonis and to the aquabirnavirus IPNV, we recommend the use of the following housekeeping genes: $U B Q, E F 1 A$ and $A C T B$, as they showed an overall stable performance in both cell types under the infection conditions.

Additional file 1: Details of the primer pairs used for real-time PCR. The table contains information about primer sequences, product sizes, annealing temperatures $(\mathrm{Ta})$, reaction efficiencies $(\mathrm{E})$, Pearson's coefficients of determination $\left(R^{2}\right)$ and melting temperatures of the amplicon (Tm) for each candidate reference gene in each cell line.

\section{Abbreviations \\ MOl: multiplicity of infection; CPE: cytopathic effect; PFU: Plaque forming unit; MEM: minimal essential medium; FBS: fetal bovine serum; RT-PCR: reverse transcription - polymerase chain reaction.}

\section{Acknowledgements}

This research was supported by grants to SHM from Conicyt (PBCT PSD08) and the Dirección de Investigación e Innovación (DI122780), Pontificia Universidad Católica de Valparaíso, Chile. AAP was supported by postdoctoral fellowship PBCT PSD08. Special thanks to Vitalia Henriquez for critical reading and helpful suggestion on the manuscript and to Claudio Jofré for IPNV sp VR299 culture.

\section{Author details}

'Laboratorio de Genética e Inmunología Molecular, Instituto de Biología, Pontificia Universidad Católica de Valparaíso, Av. Brasil 2950, Valparaíso, Chile. ${ }^{2}$ Department of Biology, University of Waterloo, 200 University Avenue West, Waterloo, ON N2L 3G1, Canada.

\section{Authors' contributions}

AAP was the first author of the manuscript, was responsible for primer design, determined the study design and performed all experimental procedures and analyses. NCB revised critically the manuscript for important intellectual content and SHM supervised the study and revised critically the manuscript. All authors read and approved the final manuscript.

\section{Competing interests}

The authors declare that they have no competing interests.

Received: 24 December 2009 Accepted: 14 April 2010 Published: 14 April 2010

\section{References}

1. Bustin SA: Quantification of mRNA using real-time reverse transcription PCR (RT-PCR): trends and problems. J Mol Endocrinol 2002, 29:23-39.

2. Huggett J, Dheda K, Bustin S, Zumla A: Real-time RT-PCR normalisation; strategies and considerations. Genes Immun 2005, 6:279-284.

3. Vandesompele J, De Preter K, Pattyn F, Poppe B, Van Roy N, De Paepe A, Speleman F: Accurate normalization of real-time quantitative RT-PCR data by geometric averaging of multiple internal control genes. Genome Biol 2002, 3:research0034.

4. Pfaffl MW, Tichopad A, Prgomet C, Neuvians TP: Determination of stable housekeeping genes, differentially regulated target genes and sample integrity: BestKeeper - Excel-based tool using pair-wise correlations. Biotechnol lett 2004, 26:509-15.

5. Andersen $C L$, Jensen $J$, Orntoft TF: Normalization of real-time quantitative reverse transcription-PCR data: a model-based variance estimation approach to identify genes suited for normalization, applied to bladder and colon cancer data sets. Cancer Res 2004, 64:5245-5250.

6. Dheda K, Huggett JF, Chang JS, Kim LU, Bustin SA, Johnson MA, Rook GA, Zumla A: The implications of using an inappropriate reference gene for real-time reverse transcription PCR data normalization. Anal Biochem 2005, 344:141-143.

7. De Witte-Orr S, Bols N: Cytophatic effects of chum salmon reovirus to salmonid epithelial, fibroblast and macrophage cell lines. Virus Res 2007 126:159-171.

8. Tafalla C, Sanchez E, Lorenzen N, De Witte-Orr S, Bols N: Effects of viral hemorrhagic septicemia virus (VHSV) on the rainbow trout (Oncorhynchus mykiss) monocyte cell line RTS11. Mol Immunol 2008, 45:1439-1448.

9. Fryer JL, Lannan CN, Garcés LH, Larenas JJ, Smith PA: Isolation of a Rickettsiales-like organism from diseased coho salmon (Oncorhynchus) in Chile. Fish Pathol 1990, 25:107-114.

10. Rojas V, Galanti N, Bols NC, Marshall SH: Productive infection fo Piscirickettsia salmonis in macrophages and monocyte-like cells from rainbow trout, a possible survival strategy. I Cell Biochem 2009, 108:631-637.

11. Jorgensen SM, Kleveland EJ, Grimholt U, Gjoen T: Validation of reference genes for real-time polymerase chain reaction studies in Atlantic salmon. Mar Biotechnol 2006, 8:398-408.

12. Ingerslev $\mathrm{HC}$, Pettersen $E F$, Jakobsen RA, Petersen $C B$, Wergeland $H$ : Expression profiling and validation of reference gene candidates in immune relevant tissues and cells from Atlantic salmon (Salmo salar L.). Mol Immunol 2006, 43:1194-1201.

13. Olsvik PA, Lie KK, Jordal AE, Nilsen TO, Hordvik I: Evaluation of potential reference genes in real-time RT-PCR studies of Atlantic salmon. BMC Mol Biol 2005, 6:21.

14. Hibbeler S, Scharsack JP, Becker S: Housekeeping genes for quantitative expression studies in the three-spined stickleback Gasterosteus aculeatus. BMC Mol Biol 2008, 9:18.

15. McCurley AT, Callard GV: Characterization of housekeeping genes in zebrafish: male-female differences and effects of tissue type, developmental stage and chemical treatment. BMC Mol Biol 2008, 9:102.

16. Ganassin R, Bols N: Development of a monocyte/macrophage-like cell line, RTS11, from rainbow trout spleen. Fish Shellfish Immunol 1998, 8:457-476.

17. De Witte-Orr S, Zorzitto J, Sutton L, Bols N: Preferential induction of apoptosis in the rainbow trout macrophage cell line, RTS11, by 
actinomycin D, cycloheximide and double stranded RNA. Fish Shellfish Immunol 2005, 18:279-295.

18. Bols NC, Lee LE: Cell lines: availability, propagation and isolation. Biochemistry and Molecular Biology of Fishes Amsterdam, ElsevierHochachka PW, Mommsen TP 1994, 3:145-159.

19. Lannan CL, Fryer JL: Extracellular survival of Piscirickettsia salmonis. J Fish Dis 1994, 17:545-548.

20. Reed $L$, Muench HA: A simple method of estimating fifty percent end points. Am J Hyg 1938, 27:493-497.

21. Jashes M, Gonzalez M, Lopez-Lastra M, De Clercq E, Sandino AM: Inhibitors of infectious pancreatic necrosis virus (IPNV) replication. Antiviral Res 1996, 29:309-312.

22. Marshall $\mathrm{SH}$, Heath $\mathrm{S}$, Henríquez V, Orrego C: Minimally invasive detection of Piscirickettsia salmonis in cultivated salmonids via the PCR. Appl Environ Microbiol 1998, 64:3066-3069.

23. Kibbe WA: OligoCalc: an online oligonucleotide properties calculator. Nucleic Acids Res 2007, 35:W43-W46[http://www.basic.northwestern.edu/ biotools/oligocalc.html], doi:10.1093/nar/gkm234.

24. Hellemans J, Mortier G, De Paepe A, Speleman F, Vandesompele J: qBase relative quantification framework and software for management and automated analysis of real-time quantitative PCR data. Genome Biol 2007, 8:R19.

25. Watson S, Mercier S, Bye C, Wilkinson J, Cunningham AL, Harman AN: Determination of suitable housekeeping genes for normalisation of quantitative real-time PCR analysis of cells infected with human immunodeficiency virus and herpes viruses. Virol J 2007, 4:130.

26. Radonic A, Thulke S, Bae HG, Müller MA, Siegert W, Nietsche A: Reference gene selection for quantitative real-time $P C R$ analysis in virus infected cells: SARS corona virus, Yellow fever virus, Human Herpesvirus-6, Camelpox virus and Cytomegalovirus infections. Virol J 2005, 2:7.

27. De Boever S, Vangestel C, De Backer P, Croubels S, Sys SU: Identification and validation of housekeeping genes as internal control for gene expression in an intravenous LPS inflammation model in chickens. Vet Immunol Immunopathol 2008, 122:312-317.

28. Fernandes JM, Mommens M, Hagen O, Babiak I, Solberg C: Selection of suitable reference genes for real-time PCR studies of Atlantic halibut development. Comp Biochem Physiol B Biochem Mol Biol 2008, 150:23-32.

29. Sirover MA: New insights into an old protein: the functional diversity of mammalian glyceraldehyd-3-phosphate dehydrogenase. Biochem Biophys Acta 1999, 1432:159-184.

30. Schmittgen TD, Zabrajsek BA: Effect of experimental treatment on housekeeping gene expression: validation by real-time, quantitative RTPCR. J Biochem Biophys Methods 2000, 46:69-81.

doi:10.1186/1756-0500-3-101

Cite this article as: Peña et al.: An evaluation of potential reference genes for stability of expression in two salmonid cell lines after infection with either Piscirickettsia salmonis or IPNV. BMC Research Notes 2010 3:101.

\section{Submit your next manuscript to BioMed Central and take full advantage of:}

- Convenient online submission

- Thorough peer review

- No space constraints or color figure charges

- Immediate publication on acceptance

- Inclusion in PubMed, CAS, Scopus and Google Scholar

- Research which is freely available for redistribution

Submit your manuscript at www.biomedcentral.com/submit
Biomed Central 